\title{
Connecting formal and informal learning to enhance elementary teacher preparation in Geosciences
}

\author{
Sharon L. Locke, Georgia Bracey, Tom Foster, Shawn Fraine, Shunfu hu, Katie lacombe, Colin Wilson \\ Center for SteM Research, Education, \& Outreach, Southern lluinois University Edwardsville, Edwardsville, IL, USA

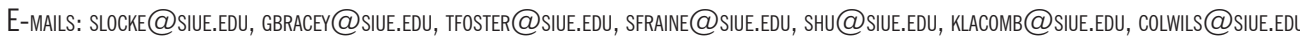

\begin{abstract}
The U.S. National Research Council has called on the science education community to conduct further studies on how informal learning complements the formal classroom environment. Responding to this research need, we are developing, testing, and studying new instructional materials that integrate informal, field-based science learning into elementary teacher education. Using EarthCaching as a model for teaching geosciences, the project team has developed an introductory module and seven field-based EarthCaching activities that connect to the earth and space science core ideas described in the Next Generation Science Standards. The materials are aimed at pre-service elementary teachers; however, they are appropriate for use with early childhood and special education majors. To date we have piloted the materials over four semesters, gathering feedback through focus groups to inform iterative revisions. Through the redesign process, the team has identified a set of preliminary design principles to guide other teacher educators interested in integrating EarthCaching into their instruction. These include attention to preparation, safety, and navigation; emphasis on observation, estimation, and prediction; promoting peer group interactions; presenting familiar sites from a new perspective; and highlighting cultural significance. Elementary pre-service teachers in the focus groups noted the value of taking young learners outside to EarthCache, including the opportunity to connect classroom learning to the real world and to teach geosciences locally. We anticipate that integrating informal science learning experiences into a science course for elementary pre-service teachers will increase their positive attitudes towards informal learning and intention to use elements of informal learning with their own students.
\end{abstract}

\section{Manuscrito:}

Received: Quadrennial Conference of the International Geoscience Education Organization

Accepted: 05/06/2018

Citation: Locke S.M, Bracey G., Foster T., Fraine S., Hu S., Lacombe K., Wilson C. 2018. Connecting formal and informal learning to enhance elementary teacher preparation in geosciences. Terræ Didatica, 14((3):282-288. URL: http://www.ige. unicamp.br/terraedidatica/.

Keywords: informal learning, teacher education, EarthCaching, elementary science education

Thematic line: "Teaching of Geosciences and Natural Sciences for School-Level Education and Teacher Training"

\section{Introduction}

Historically, Geosciences have been taught inconsistently to future elementary teachers (Trygstad et al. 2013). Many elementary teachers enter their practice lacking exposure to the full range of scientific topics, which may contribute to a belief that they are unprepared to teach science (Plotnick et al. 2009). The adoption of the Next Generation Science Standards (NGSS) in the United States increases the urgency for finding new and effective approaches for teacher education in the geosciences that will ultimately benefit students across multiple grade levels. The NGSS elevates earth and space sciences to one of the four domains for science learning (physical sciences; life sciences; and engineering, technology, and applications of science are the other three). The NGSS Fra- mework provides the most essential ideas in science that all students should understand by the time they finish high school, framed as performance expectations (PEs) that integrate the disciplinary core ideas, science and engineering practices, and crosscutting concepts (National Research Council 2012). This three-dimensional learning (Krajcik et al. 2014) contrasts with current practice and necessitates a substantial shift in instruction to in-depth development of core ideas (as opposed to breadth), a central role for scientific and engineering practices, and coherence in building ideas across time and between science disciplines (Reiser 2013). The Framework presents a challenge for any science teacher, but may be especially daunting for elementary-level teachers, who often report discomfort with teaching science and mathematics (Michaels et al. 2008). 
We are addressing lack of teacher preparation in Geosciences by testing a new model for instruction in a science content course for elementary education majors. Our model integrates principles of field-based experiences and informal learning using the highly successful international EarthCaching program as a foundation for teacher candidates' learning. The materials we are developing are a means for future teachers to develop deeper content knowledge in the geosciences through field activities and increase their understanding of the NGSS, thus improving their preparation for a teaching career.

\section{Background}

\subsection{EarthCaching}

EarthCaching (www.earthcache.org) is a program that engages hundreds of thousands of people each year in a participatory earth science informal learning experience. EarthCaching is a derivative of geocaching, an activity in which an individual or group uses GPS (Global Positioning System) technology to find a hidden "cache," often a plastic box with an object or logbook in it. Geocaching is a fun treasure hunt that is hugely popular and beneficial in getting people to be active outdoors. EarthCaching takes the geocache idea a significant step forward in that it is designed to promote science learning. An EarthCache has no physical box or paper logbook; instead it presents an earth science lesson that engages the individual in learning something about how an area formed geologically, or why it is important scientifically. The educational activity is written for a non-technical audience and highlights the unique aspects of a field site. Although EarthCaching has reached over four million people around the world since it began in 2004, research on EarthCaching is limited. Our prior work has examined adult participants' experiences and the potential of the program to increase content knowledge, develop interest, and promote deep engagement in science (Locke, Bracey, \& Lewis 2014). The current study focuses on the potential of EarhCaching to enhance teacher education.

\subsection{Situated Learning}

The theoretical framework for this study is based on Brown, Collins \& Duguid's (1989) perspective on situated learning theory. These authors argued that the typical practices of schooling
(...) deny students the chance to engage the relevant domain culture because that culture is not in evidence...[thus], students may pass exams (a distinctive part of school cultures) but still not be able to use a domain's conceptual tools in authentic practice (Brown et al. 1989, p. 34).

Applied to geoscience education, situated learning theory suggests that learning geoscience processes decontextualized from an authentic field setting is unlikely to be successful. When an activity such as interpretation of topography is transferred to the classroom, authenticity is lost and students participate in classroom tasks that are situated within the school culture. "Students are likely to misconceive entirely what practitioners actually do," and this can result in negative perceptions of the domain (Brown et al. 1989, p. 34).

Field-based learning and informal (out-of-school) learning provide opportunities for learning about the geosciences in an authentic context. These two design principles, described in the next sections, underpin the project.

\subsection{Field-Based Learning}

Several authors have documented the benefits of field experiences for science learning (Orion 1993; Orion \& Hofstein 1994; Rickinson et al. 2004; Elkins \& Elkins 2007; Tretinjak \& Riggs 2008; Mogk \& Goodwin 2012). Research has consistently shown that students have positive attitudes towards field trips (Eshach 2007) and that learning science out-of-school adds authenticity and relevance (Braund \& Reiss 2006). In the geosciences, field work enables students to contextualize ideas that have been presented in classrooms (Orion 1993; Orion \& Hofstein 1994) and to observe spatial relationships in three dimensions (Kali \& Orion 1996). Furthermore, the mode of instruction used during a field experience affects student outcomes (Hawley 1996). Students who participated in a guided-inquiry, student-centered field trip developed a deeper understanding of geological concepts than those on a lecture-based or virtual field trip (Tretinjak \& Riggs 2008).

Pre-service teachers are not usually trained for leading field trips (Mason 1980, Hofstein \& Rosenfeld 1996, McKeown-Ice 2000, Griffin 2007, Tretinjak \& Riggs 2008) and not surprisingly, practicing teachers rarely teach science outdoors (Keown 1986, Rickinson et al. 2004). As observed by Rebar \& Enochs (2010), teachers face a number of exter-

\begin{tabular}{c|c|c|c|c|c|}
\hline (C) Terrae Didat. & Campinas, SP & v.14 & n.3 & $282-288$ & jul./set. 2018 \\
\hline
\end{tabular}


nal challenges in implementing organized field trips, including time constraints that limit opportunities for exploration in an outdoor setting. EarthCaching provides an alternative to a teacher-led field trip, affording participants the time to explore new surroundings and be open to surprise events (e.g., an animal encounter, changing weather) that extend learning. Additionally, EarthCaching offers an example of a "close-to-home" solution for getting children into the field. Exposure to EarthCaching during an undergraduate teacher preparation program raises elementary teachers' awareness of the range of options for field-based learning, increasing the likelihood that they include field work in their practice.

\subsection{Informal Learning}

Only $18.5 \%$ of K-12 students' waking hours are spent in school (LIFE Center 2005). STEM learning involves activities within a broader "learning ecosystem" that "encompasses schools, community settings such as after-school and summer programs, science centers and museums, and informal experiences at home and in a variety of environments" (Traphagen \& Traill 2014, p. 2). Informal learning environments are characterized by opportunities for students to follow their interests, learn STEM in real-word contexts, and work on problems relevant to their own daily lives.

School settings have the potential to reinforce positive mindsets for lifelong learning in STEM. Teachers generally welcome opportunities to include field trips to museums, nature centers, and other off-site locations; however, budgetary and time pressures continue to limit opportunities for experiences in informal settings. Creative solutions for integrating formal and informal learning in ways that nurture children's interests and support access to learning for all students are needed. Adams and Gupta (2015) found that aspiring teachers' benefited from informal teaching practicums in a natural history museum, and that these experiences influenced their identity as a science teacher. Our project builds on their findings, looking more deeply at teacher candidates' attitudes and intentions for their future classrooms.

\section{Goals and Objectives}

The project aims to increase future elementary teachers' preparation to teach earth science through field-based experiences. We anticipate that integrating a set of self-directed field-based learning activities into a course for elementary education majors will increase their geoscience content knowledge, knowledge and skills related to field-based education, intention to teach geoscience in their own classrooms, and positive attitudes towards linking formal and informal learning. The following are the three project objectives:

1. Develop and test an EarthCaching-based geoscience curriculum for an undergraduate science content course for elementary education majors;

2. Examine student learning outcomes using qualitative and quantitative research methods;

3. Examine changes in teacher candidates' attitudes and intentions towards informal learning.

This is an ongoing project and we are currently refining a set of EarthCaches and the research instruments. This paper presents our results from the EarthCache design and development process (above, Objective 1).

\section{Methods}

A team composed of three geoscience educators, a science education researcher, and a statistician are collaboratively developing and testing a set of EarthCaches located on or near the campus of a public master's comprehensive university in the Midwestern U.S. The EarthCaches are being tested in a one-semester general science course for elementary education majors with an emphasis on hands-on, inquiry-based daily laboratory projects. The course is the first in a sequence of two courses, with the other course focusing on biology and chemistry. There are 24 instructional units covering physics and earth and space science topics. Students begin each class working in teams on a question-based activity aligned with the $5 \mathrm{E}$ instructional model (engage, explore, explain, elaborate, evaluate) (Bybee et al. 2006) that students can adopt in their own future classrooms. The activity ends by collecting and sharing student observations and inferences to support learning of the concept. The concept is expanded upon by a short lecture by the instructor and further evaluated with on-line homework. The explicit goal of the activities is to model how to teach a student-centered class, with the goal that the future teachers will use these techniques. 
The project has created seven field-based EarthCaches that reinforce concepts taught during the lecture/laboratory portion of the course: Topography, Soils, Water Cycle, Rock Cycle, Illinois Watersheds, Natural Resources - Coal Mining, Natural Resources - Landfills. Additionally, the Introduction to EarthCaching online module has been developed and implemented in the same four sections over two semesters. The introductory module is presented during a class session as a PowerPoint presentation, and then made available to students in the Blackboard course management system for them to access at any time. The online version of the module includes supplementary materials that provide further information on the three topicsglobal positioning system (GPS), regional geology, and EarthCaching and its relevance to formal and informal learning.

Three EarthCache field-based modules (Topography, Soils, and Watersheds) have been piloted in four different sections of the science course during the fall semester 2016 and spring semester of 2017. Four additional EarthCaches (Water Cycle, Rock Cycle, Natural Resources - Coal Mining, Natural Resources - Landfills) have been piloted along with the original three in summer and fall of 2017, and also in spring of 2018. After each semester of piloting, the team collects student feedback to inform revisions to the EarthCaches, resulting in an iterative design cycle.

In the fall of 2016, using a brief questionnaire (seven open-ended questions), the research team collected written feedback from eight students who completed the first three EarthCaches on their own time for extra credit. The results of the questionnaires indicated generally favorable reactions from the students as well as some specific recommendations to improve the wording of questions and the formatting. In spring of 2017, the team conducted two focus groups with a total of five participants who had completed the EarthCaches for extra credit. These participants were asked the same questions as on the fall 2016 questionnaire (e.g., what went well, what was challenging, how the activity aligned with classroom content, and the pros and cons of implementing an EarthCache activity in a formal classroom setting), as well as questions on how to improve the activity and which part was most/least enjoyable. In summer 2017, five first- or second-year undergraduate students who had declared an intention to major in science, math, or engineering completed the EarthCaches as part of a summer internship and responded to a written questionnaire. In fall of 2017, the team conducted eight focus groups with approximately 20 participants from the science course for elementary education majors who had completed the EarthCaches as part of their course work and for extra credit.

\section{Results and Discussion}

\subsection{Results - Focus Groups}

Focus group data show some common responses and impressions from the undergraduate students who piloted the EarthCaches. In the earlier focus groups, one of the biggest frustrations for participants involved the navigation aspect of the activities-working with coordinates and the GPS units. Some participants felt unsure that they were in the right place and were relieved when they found the correct location. A few reported having trouble downloading maps, using Google Earth to find certain points, and operating the GPS units.

Despite these challenges, some participants reported that the EarthCaches aligned with what they were learning in class and that they were surprised to discover many aspects of campus that they had not noticed before.

"Seeing what you see every day in a new perspective was interesting... to try to notice stuff that you don't really look at all the time." (Focus Group, FA17)

"I liked the landfill most because I didn't know the landfill existed until then." (Focus Group, FA17)

Furthermore, participants felt that elementary students would benefit from making real-world connections and would have fun being outside, although these activities might be time-consuming for teachers to implement. The participants enjoyed socializing while walking or driving around campus as they looked for the sites. The participants were positive about using EarthCaches in a classroom setting, often talking about the importance of "doing," and being "hands-on" rather than just reading or listening.

"It was definitely fun getting outside though and not just seeing pictures on a slide show or a presentation... actually seeing it for ourselves" (Focus Group, FA17)

\begin{tabular}{c|c|c|c|c|c|}
\hline (C) Terrae Didat. & Campinas, SP & v.14 & n.3 & $282-288$ & jul./set. 2018 \\
\hline
\end{tabular}


Participants also spoke about the excitement of going outside for young students, and a few participants felt that students would actually focus better outside.

"Just to be able to take them outside to look at water or to look at different soil... hands on for kids, especially young kids, in short stints, is extremely helpful. And the energy... it helps because it's not trapped. Outside they can focus better because even though there's many more options, that energy of walking around is usually enough for them to help [focus]." (Focus Group, SP17)

Some mentioned that an EarthCache could be like a field trip, with the advantage of not needing to go far from the school.

\subsection{Implications for EarthCache Development}

After each pilot in a semester we used the focus group data to inform revisions to the EarthCache materials. Many of the comments from students indicated that the EarthCache experience would be perceived more positively if students had clearer information about what they could expect. Navigation was frequently mentioned as an area for improvement, so a diagram showing parking locations and/or photographs showing the view from the EarthCache location were added to help students' wayfinding. Students sometimes expressed frustration with the weather or distance they had to walk, so two new sections were included: "Know Before Your Go" and "Things To Bring." These sections provide information on walking distances, a description of the walking surfaces, potential seasonal changes at the site, and recommendations on items to bring to enhance the experience, such as binoculars. These additions helped reduce the uncertainties related to logistics, so that students were better prepared to focus on learning.

Each EarthCache includes a set of questions to answer about the site, such as "what are the main components of the soil at this location?" and "how might you expect the site to be different after a period of high rainfall?" The goal is to encourage students to observe carefully and apply concepts they are learning in the classroom to what they are seeing in the field, but also to be open to new discoveries. This open-endedness can be frustrating for some students; however, the open-endedness is consistent with the principles of informal science learning. To alleviate student concerns about not knowing the "right" answer, the activity is not assessed with a formal grade. Although the project team considered revising questions so that students would find them "easier" to answer, for now we have focused only on making sure the wording is clear, and have not made an effort to simplify the questions.

\section{Recommendations and Future Work}

To guide educators interested in developing local EarthCaches for teacher training, we propose a set of emerging design principles. Elementary preservice teachers may have limited field experiences in their university courses and may be less familiar with or less confident with scientific content. To ensure comfort and minimize concerns, background information in the EarthCache materials should address both logistics (such as weather) and learning (emphasis on observation and critical thinking). Our preliminary recommendations for EarthCache design include the following:

1. Include preparation and safety information, such as walking distances, expected time to complete the EarthCache, types of walking surfaces, and any potential hazards.

2. Provide a list of equipment that is needed or could enhance the field experience, such as a magnifying glass, binoculars, measuring tape, or camera.

3. Take time to ensure that the participant understands the Earth coordinate system and how to navigate using GPS, a mapping program, or both.

4. Include questions that emphasize observation, estimation, and prediction.

5. Encourage participants to complete the activities with a peer of family member, which encourages discussion and allows different perspectives to be considered.

6. Choose sites that align with science learning objectives, and be willing to consider seemingly "ordinary" locations. Students appreciate being asked to look at something familiar in a new way.

7. When possible, develop EarthCaches at sites that have social, cultural, or historical significance. Participants frequently chose our landfill EarthCache as a favorite. This site does not have

\begin{tabular}{c|c|c|c|c|c}
\hline (C) Terrae Didat. & Campinas, SP & v.14 & n.3 & $282-288$ & jul./set. 2018 \\
\hline
\end{tabular}


beautiful scenery, but the students were able to connect the nearby landfill to their own actions, and recognize they were seeing an outcome of resource use on the university campus.

An instructor-led EarthCache during course time can increase comfort with field-based learning by giving students time to become familiar with navigation, facilitating group discussion, and enabling the instructor to model observation skills and comfort with not knowing all the answers. The benefit of a field-based experience is that surprises are possible when learning takes place outside a controlled classroom environment (the appearance of an unusual animal or an unanticipated change to site conditions). EarthCaches help encourage future teachers to become comfortable with facing something that is unfamiliar, and may lead them to ask new questions about their surroundings as they look at the landscape in a new way. This sparking of curiosity is at the core of informal learning, and we argue that connecting formal education of elementary pre-service educators with informal learning activities improves their preparation to teach.

This project is ongoing, and as the EarthCaches are piloted in additional course sections the materials will be further refined. An important goal is to create EarthCaches that are accessible to people with different physical abilities, so we will be adding features that align with principles for universal design in science learning. This includes converting the printed version of the EarthCaches to an online version, so that participants who choose to do so can enter their answers to questions using a mobile device through voice recognition. Ultimately, we hope that the EarthCaches will increase awareness of the geosciences in this region. The EarthCaches developed for this project will be submitted to the EarthCache organization for official approval. The approval process will also need to include university administrators, since making the EarthCaches available to the public could increase traffic on campus.

The final products of this project will include the Introduction to EarthCache module, a set of field-based EarthCaches, two virtual EarthCaches, and a guide for pre-service elementary teachers on how to develop and integrate EarthCaches into their own future classrooms. All these educational materials will be made available at no cost on our university's website.

\section{Acknowledgements}

This material is based upon work supported by the National Science Foundation under Grant Number DUE-1608515. Any opinions, findings, and conclusions or recommendations expressed in this material are those of the author(s) and do not necessarily reflect the views of the National Science Foundation.

\section{References}

Adams J.D., Gupta P. 2015. Informal science institutions and learning to teach: An examination of identity, agency, and affordances. Journal of Research in Science Teaching. DOI: 10.1002/tea.21270.

Braund M., Reiss M. 2006. Towards a more authentic science curriculum: The contribution of out-ofschool learning. International Journal of Science Education, 28(12):1373-1388.

Brown J.S., Collins A., Duguid P. 1989. Situated cognition and the culture of learning. Educational researcher, 18(1):32-42.

Bybee R., Taylor J.A., Gardner A., Van Scotter P., Carlson J., Westbrook A., Landes N. 2006. The BSCS 5E Instructional Model: Origins and Effectiveness. Colorado Springs, CO: BSCS.

Elkins J.T., Elkins N.M. 2007. Teaching geology in the field: Significant geoscience concept gains in entirely field-based introductory geology courses. $J$. Geosc. Educ., 55(2):126.

Eshach H. 2007. Bridging in-school and out-of-school learning: Formal, non-formal, and informal education. J. Sci. Educ. Technol., 16(2):171-190.

Griffin J. 2007. Students, teachers, and museums: Toward an intertwined learning circle. In J.H. Falk, L.D. Dierking, S. Foutz eds. 2007. In Principle, In Practice: Museums as Learning Institutions. Lanham, MD: Rowman Altamira. p. 31-42.

Hawley D. 1996. Changing approaches to teaching earth science fieldwork. In D.A.V. Stow, J.G. McCall eds. 1996. Geoscience Education and Training: In Schools and Universities, for Industry and Public Awareness (AGID special publication series, 19, pp. 243-253). Rotterdam: A.A. Balkama.

Hofstein A., Rosenfeld S. 1996. Bridging the gap between formal and informal science learning. Studies in Science Education, 28:87-112.

Kali Y., Orion N. 1996. Spatial abilities of high-school students in the perception of geologic structures. J. Res. Sci. Teaching, 33(4):369-391.

Keown D. 1986. Teaching science in US secondary schools: A survey. The Journal of Environmental Education, 18(1), 23-29.

Krajcik J., Codere S., Dahsah C., Bayer R., Mun K. 2014. Planning instruction to meet the intent of the Next Generation Science Standards. J. Sci. Teacher Educ., 25(2):157-175.

LIFE Center. 2005. The LIFE Center's Lifelong and Lifewide Diagram. Stevens R., Bransford J., Stevens A. Retrieved October 24, 2015 from http://www. life-slc.org/about/about.html. 
Locke S., Bracey G., Lewis G. 2014. Who EarthCaches and why: Results of an exploratory survey. Geological Society of America Abstracts with Programs, 46(6), 243.

Mason J.L. 1980. Field work in earth science classes. School Science and Mathematics, 80(4):317-322.

McKeown-Ice, R. 2000. Environmental education in the United States: A survey of preservice teacher education programs. The Journal of Environmental Education, 32(1):4-11.

Michaels S., Shouse A., Schweingruber H. 2008. Ready, set, science! Putting research to work in K-8 science classrooms. Washington, D.C: National Academies Press.

Mogk D.W., Goodwin C. 2012. Learning in the field: Synthesis of research on thinking and learning in the geosciences. In Kastens K.A., Manduca C.A. eds. 2012. Earth and Mind II: A Synthesis of Research on Thinking and Learning in the Geosciences. Geological Society of America Special Papers, v. 486, p. 131-163.

National Research Council (NRC) 2012. A Framework for K-12 Science Education: Practices, Cross-Cutting Concepts, and Core Ideas. Washington, DC: The National Academic Press.

Orion N. 1993. A model for the development and implementation of field trips as an integral part of the science curriculum. School Science and Mathematics, 93(6):325-331.

Orion N., Hofstein A. 1994. Factors that influence learning during a scientific field trip in a natural environment. J. Res. Sci. Teaching, 31(10):10971119.
Plotnick R.E., Varelas M., Fan Q. 2009. An integrated earth science, astronomy, and physics course for elementary education majors. J. Geosc. Educ., 57(2):152-158.

Rebar B.M., Enochs L.G. 2010. Integrating environmental education field trip pedagogy into science teacher preparation. In: A.M. Bodzin, B. Klein, S. Weaver. eds. 2010. The inclusion of Environmental Education in Science Teacher Education. The Netherlands: Springer. p. 111-126.

Reiser B.J. 2013. What professional development strategies are needed for successful implementation of the Next Generation Science Standards. In: Paper written for the Invitational Research Symposium on Science Assessment, September (v. 24, p. 25).

Rickinson M., Dillon J., Teamey K., Morris M., Choi M.Y., Sanders D., Benefield P. 2004. A review on outdoor learning. Field Studies Council, Shrewsbury, UK.

Traphagen K., Traill S. 2014. How Cross-Sector Collaborations are Advancing STEM Learning. Los Altos, CA: Noyce Foundation.

Tretinjak C.A., Riggs E.M. 2008. Enhancement of geology content knowledge through field-based instruction for pre-service elementary teachers. $J$. Geosc. Educ., 56(5):422-433.

Trygstad P.J., Smith P.S., Banilower E.R., Nelson M.M. 2013. The Status of Elementary Science Education: Are We Ready for the Next Generation Science Standards? Retrieved October 2, 2014 from http:// www.horizon-research.com/horizonresearchwp/ wp-content/uploads/2013/12/The-Status-of-Elementary-Science-Education_paper.pdf 